\title{
When the Real Really Means: VR and AR Experiences in Real Environments
}

\author{
Giorgio Verdiani \\ Ylenia Ricci \\ Andrea Pasquali \\ Stéphane Giraudeau
}

\section{Abstract}

During this past year the Laboratory for eXtended Realities (DIDA-LXR) from the DIDALABS system at the Department of Architecture at the University of Florence, has experienced a various number of activities. Most of them linked together digital modelling of no longer existing architectures and still in place Built Heritage. Others were aimed to develop an "Augmented Virtual Reality" using specific environments/locations (for example a boat) to enhance the sensations of the user during the experience. Some others were based on direct VR shooting, using advanced panoramic cameras and creating a point of view compliant with the specific impressions that the place should transmit. In the contribution proposed here the AR, VR and XR experiences from this personal research will be presented sharing the specific subjects, the evaluation of usable technologies, the strategy for shooting, survey, processing and post-processing, the dissemination of ideas and the lesson learnt.

\section{Keywords}

virtual reality, augmented reality, photogrammetry, aerialphotogrammetry.

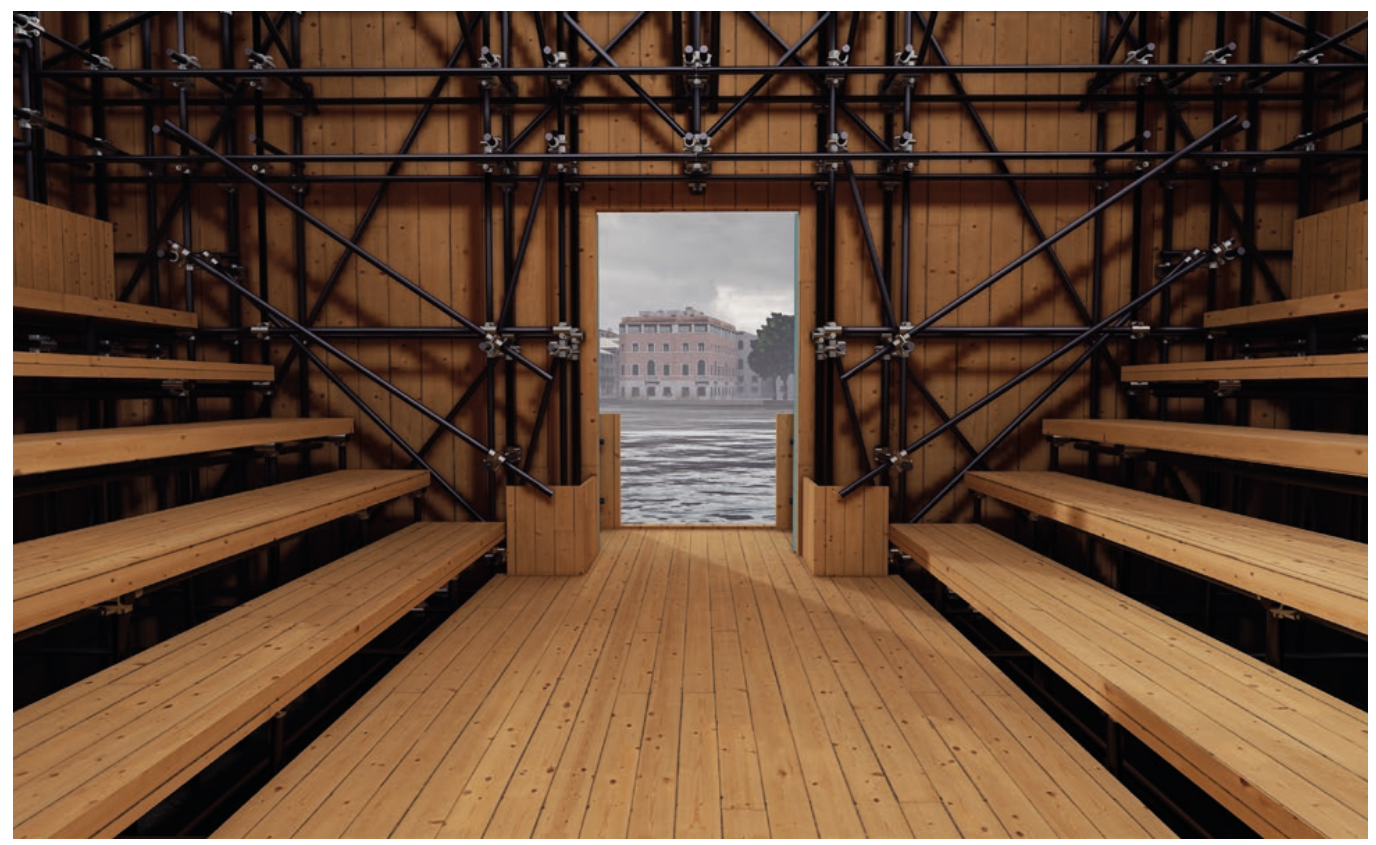




\section{Introduction}

The new possibilities created by the Laboratory for eXtended Reality were immediately followed up with case studies applied to cultural heritage. We consider the possibility given by virtual environments and augmented reality a great potential for reading and study, the way to increase and facilitate the knowledge of the architectural heritage.

This technological development has led us to the need to deepen the existing possibilities of recording or surveying the existing. The growth of this knowledge has allowed us to think about topics that have a key theme and to experiment with new possibilities of fruition and use of the collected data. The whole set of experiences was oriented to Mediterranean subjects connecting the eastern and western parts of the "Mare Nostrum". In this way, the Medusa's Heads passing from Constantinople to Istanbul, the Tetrarchs' Statue in Venice, the Venetian Lagoon and its story, becomes the first series of fragments of a VR and AR plot around the Mediterranean Sea. The approach is to create a versatile set of multimedia elements, oriented to work in a "classic" environment like the traditional display as well as in modern solutions like the immersive visors. At the same time, while experimenting with different solutions and subjects, specific attention was given to the users' experience, gathering information and suggestions from the people using the virtual/augmented environments. This was quite useful in addressing and enhancing the further developments of models and proposals. The guidelines followed in all the testings and experiments were aimed at the production of very persuasive environments enriched by fascinating and valuable contents.

\section{From Site to Virtualization}

The paper presents experiences of eXtended Reality that aim to increase the user's sensory perception. This evolution is not sought by artificial technological inputs but by the real environment. Analyzing and structuring the real physical location where to place the device for the use of the digital environment we aim to add real inputs to complete the virtual experience. From this, the cases presented are strongly different and distinguishable but with a common theme. The research wants to focus on the need to link the place of the fruition of the virtual environment with the digital product. This is to have a more complete product. However, do not want to take away the importance of the greatest potential of Virtual Reality, that of relating to the object of study in an environment completely parallel and independent from physical reality, releasing the digital object from the real world. The reasoning wants to underline how eXtended Reality is not only the trivial union of $A R$ and VR but it finds complete fulfilment in the knowledge and in the dialogue with the environment in which the experience takes place. Not only structuring and engaging with the location but also welcoming (and possibly shielding) the stimuli and features that are part of it.

\section{Case Study One: the Theater of the World by Aldo Rossi}

The first step in our journey to rediscover the Mediterranean Sea is Aldo Rossi's Theatre of the World [Brusatin \& Prandi, 1982]. This iconic temporary architecture was built between the late seventies and early eighties and it has represented the symbol of what is known as temporary installations. Created specifically for the Venice Biennale of Architecture in 1979 [Garcia 2006] still recalls more than 30 years later, the typical charm of something that was once there and now no longer exists, if not virtually. The purpose in this research is to keep this feeling of curiosity alive and untouched and then fulfil it, thanks to the development of a virtual environment, in which it has been relocated the Theater.

The process behind the virtualization began with the documentation about the architecture and it was necessary to collect information about the structure and the form of the building itself, using architectural drawings and various photographic sources. Thereafter it was possible to carry out the digital modelling of the object, performed with Maxon Cinema 4D and then exported in Unreal Engine for the virtualization of the environment. The experience led to the digital rebirth of this disappeared architecture (fig. I). 
The virtual tour was also designed as a place of education for students, including information points making the experience active. Following the example of the Biennale, it was decided to set up a temporary installation on a boat to create the dialogue with the real environment using the external inputs given by the location itself, and in this case, the movement of the boat and the sound of the water.

Part of our research is also focused on another type of reality that allows us to create an overlay of the reality we find ourselves within. The model was reshaped and re-textured and the process was carried out specifically to obtain a digital model suitable for augmented reality and dedicated software developing a beta version of an application for IOS devices using ARKit. The aim was to showcase the effectiveness of Augmented Reality technology as a powerful tool that can be successfully applied to the research process and the communication of the Cultural Heritage.

Fig. I. The theater of the World reconstructed in its virtual space using Epic Games Unreal software, view of the virtual tour in the Basilica Cistern: view from a Panorn, view from a Panoramic VR shot taken in Poveglia; detall of the Tetrarchs statue in Venice from the sketchfab.com platform.

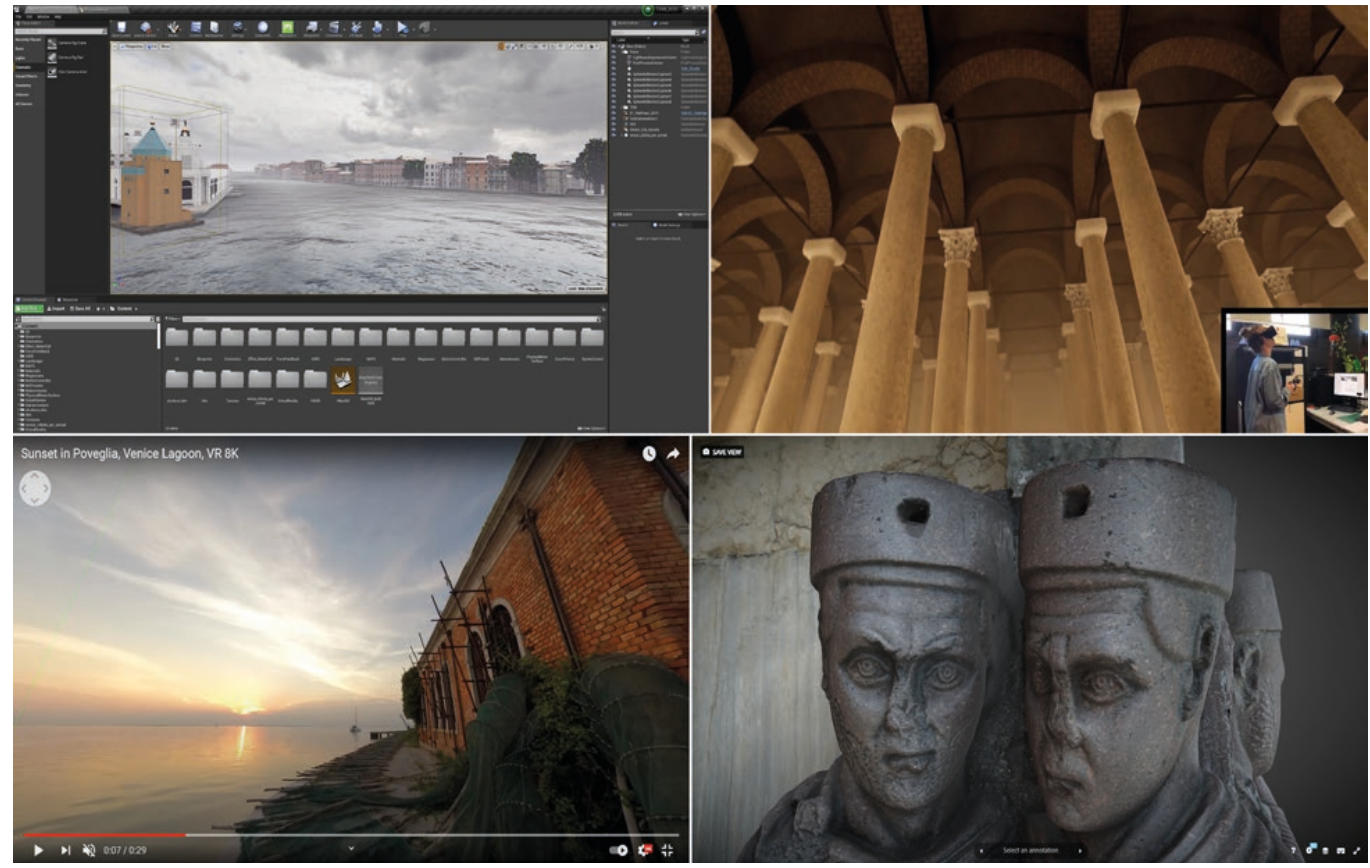

\section{Case Study Two: The Medusa Protomes Inside the Basilica Cistern}

It is safe to say that to know better Venice it is essential to know Constantinople. The two cities were strongly linked by commerce, art exchange and share some robust environmental aspects. The Basilica Cistern, in Turkish Yerebatan Sarnici, is one of the largest ancient sites below the ground of Istanbul, built by the Emperors to satisfy residents' water needs. Inside the building, under two of the 336 columns, we can find the Medusa Protomes, elements of interest not only for their history but also for the mystery about their origin [Verdiani et al. 2019]. The reconstruction of the Basilica Cistern was based on existing surveys, creating a digital model, optimally proportioned and that responds to the real [Ricci et al. 2018]. The Unreal Engine software was used to rebuild the Cistern in a virtual environment and to offer a format that can be reused in any museum context. Inside the tour the users have access to a series of multimedia containing information about the site, about the myth that lies behind the medusa protomes and the recontextualization hypothesis proposed. This is the exact demonstration of the quality of this kind of result, which is an active type of communication that offers the simulation of a real environment and an unforgettable experience enhanced in this case by the utilization of some recorded sounds captured inside the Cistern during the survey. A short video about the virtual tour in the Basilic Cistern in Istanbul can be seen in Youtube at the following link: https://youtu.be/LsrxRaDrAo0. 


\section{Case Study Three: Venice the Tetrarchs Statue}

The Tetrarchs statue in St. Marco Square, Venice, is a clear sample about reuse of spolia as a demonstration of continuity and tells a yet partially mysterious story of artworks moving around the Mediterranean during strong and dramatic historical events [Dorigo 2014]. Such an element, stable and solid across the centuries, but at the same time capable of a long and adventurous journey in its past [Missagia 20 I5], rich in references and symbols, apparently capable of hiding some intriguing stories and worth to be admired in its details [Rees 1993], was found ideal for mixing two different modern digital approaches. A VR 360 short movie, recorded in timelapse mode was taken just in front of the statue, in a quite crowded hour, in the moment when the light of the sun is moving and the shadows are going to cover the corner. This short video clip was built to enhance the perception of the place with the special relationship between the static pose of the Tetrarchs and the fluid movement of tourists and workers all around the square, with the option of having a fully dynamic $360^{\circ}$ point of view. The shooting was operated using an Insta360 Pro II camera, capable of taking 8K resolution movies and stitching them in real-time.

The video can be seen on youtube in the DIDA-LXR channel at: https://youtu.be/xqvE I Huiqfc.

To satisfy the need of details and allow a complete exploration of the sculpture, photogrammetry was operated using a Nikon D800e. The full set of shots was then processed using Reality Capture software and producing a fully textured model of about 500 million triangles, later simplified to five million and loaded with high resolution texturing on the Sketchfab.com platform and visible at https://skfb.ly/6UZ8P.

These two digital products connected each other using simple links, allow a double and quite different reading and seeing this special corner in Venice, offering a better understanding of the context and specific details in a way otherwise impossible in place, a valid alternative to the direct visit, but also stimulation and invitation to go in place and complete the knowledge about this migrating stone.

\section{Case Study Four: Poveglia, the Abandoned Island}

On the occasion of a recent trip in Venice, it was discovered a particular tiny island located inside the Venetian Lagoon named Poveglia offering the opportunity to test and discover the potential of a new tool, the Insta360 Pro 2 camera on a very fascinating environment where historic elements and urban legends are mixed [Cavallo \& Visentin 2020]. After having chosen the right spots from which shot and film, the data was processed and it has been created a 360 tour that gives everyone the chance to visit the island. It has proved to be a very useful tool and methodology for the dissemination of information about the existing heritage.

A series of Panoramic VR videos can be seen in Youtube in the DIDA- LXR Channel, at: https://youtube.com/playlist?list=PLB5GHBSIDCa-u7-e I CQrAvQ I nEmpKZLKk

Speaking of useful tools for surveying and photogrammetry, which in recent years have made significant advances in technology and functionality, we can not help but think of drones (UAV - Unmanned aerial vehicle), and the support they give in a survey thanks to their potential and the ability to access a point of view previously unthinkable.

It is possible to recreate a 360 panorama, later navigable, using the flight application of the aircraft. The method is quite simple, taking advantage of the panoramic mode 360 , the drone, autonomously, takes a series of photos in about 40 seconds in order to develop a navigable overview through the drone's piloting APP: FreeFlight 6. A sample of the result obtained from this procedure can be seen in the DIDA-LXR Youtube channel at: https://youtu.be/cjJz37JYDAU

For the flights the drone used was a Parrot Anafi. The drone weight was reduced to 300 grams in order to perform non-critical operations also in an urban context, as required by the regulations in force at the time of the flight. 


\section{Conclusion}

The present paper is composed by a sequence of studies with highly diversified contents. As stated in the initial part of the paper, the relationship with the resulting digital products has been accurately analyzed, trying to increase the virtual experience, creating a direct network between the fascination of the stories, the impression coming from the real places and the option offered by the digital solutions.

The desire of experimenting and the will of building specific and effective results is at the base of a research aimed to find efficient solution for presenting parts of the Built and Cultural Heritage in the way they deserve exploiting their best characteristics, creating a specific digital version that is an enhancement or an alternative to the real but that doesn't ask the user to settle for quality and experience, it simply provide a digital approach offering the digital version of that cultural values. The case of the Theater of the World is totally concepted as a dialogue between the location and the virtual reality, increasing the senses' suggestion. In this sense the statue of the Tetrarchs has opposite features, creating interest in something existing as a rich evidence of interactions in the Mediterranean area, the detailed photogrammetry links the real existing with virtual perceptions of knowledge and (maybe) with a desire of completion and investigation about the mysterious and impossible to be told story of its moving from Costantinople to Venice. The other two themes provide the possibility of new points of analysis, which move away from the theme in the studio but still keep close contact with the stimulus coming from the real, such as the introduction of recorded environmental sounds, in the case of the Protomes of Medusa.

This set of experiences have a value that goes far beyond describing the themes and illustrating technologies and methods. They are traces of the experiences and above all provide "a way" about sharing points, suggestions, fascinations, they try to create a specific link between the inner value of stories and places in the continuous tentative of enriching the digital contents with valuable learning occasions. Not only in the will of "capturing" the users, but in the true belief that "Digital Heritage" is an occasion allowing an easier reading and an option for spreading the knowledge of Cultural Heritage, but it need a correct comprehension of these values which is the first real step in creating a constructive system based on a sort of circular flow of attraction -> exploration $\rightarrow$ > knowledge $\rightarrow>$ digitalization $\rightarrow>$ dissemination $->$ learning $\rightarrow>$ spreading $->$ attraction.

\section{References}

Brusatin Manlio, Prandi Alberto (eds.) (1982). Teatro del mondo / Aldo Rossi. Venezia: Cluva.

Busato Davide, Sfameni Paolo (20 I 8). Poveglia: L'isola alle origini di Venezia. Venezia: Lunargento.

Cavallo Federica Letizia, Visentin Francesco (2020). "The world's most haunted island" Ghost narratives and practices around Poveglia, an abandoned island in the Venetian Lagoon. In Shima Journal, I4 (I), pp. 194-2II.

Dorigo Wladimiro (2004). Spolia marmorei d'oltremare a Venezia (secoli XI-XIV). In Saggi e memorie di storia dell'arte, 28, pp. I- I3.

García Carolina Beatriz (2006). II teatro del mondo: Aldo Rossi (1979-1980). In DC Papers. Revista de crítica i teoria de l'arquitectura, 15, pp. |46-|49.

Missagia Andrea (20I5). Spolia Costantinopolitani. II Gruppo dei Tetrarchi a Venezia. Esposizione seminariale "La piazza di San Marco a Venezia", Storia dell'Arte del Veneto Medievale Sp. - Università Ca' Foscari di Venezia, a.a. 20 I4/20I5, Italy.

Rees Roger ( 1993). Images and Image: A Re examination of Tetrarchic Iconography. In Greece \& Rome, Second Series, 40 (2), pp. I 8 I -200.

Ricci Ylenia, Verdiani Giorgio, Pasquali Andrea (2018). A Petrified Petrifying Eyesight: A Story for the Medusa's heads from Istanbul, Turkey. In Proceedings of the 23rd International Conference on Cultural Heritage and New Technologies 20 I 8. CHNT 23.

Verdiani Giorgio, Ricci Ylenia, Pasquali Andrea (2019). Mito, Pietra, Spolia e Storia, Frammenti di indefinito da Costantinopoli a Istanbul. In Conte Antonio, Guida Antonella (eds.), ReUso Matera Patrimonio in Divenire conoscere valorizzare abitare. Roma: Gangemi, pp. 1203-1214.

\footnotetext{
Authors

Giorgio Verdiani, Dept. of Architecture, University of Florence, giorgio.verdiani@unifi.it

Ylenia Ricci, Dept.of Architecture, University of Florence, ylenia.ricci@unifi.it

Andrea Pasquali, Dept. of Architecture, University of Florence, andrea.pasquali@unifi.it

Stéphane Giraudeau, Dept. of Architecture, University of Florence, stephane.giraudeau@unifi.it
} 
